\title{
Anaerobic fungi linked to ancient methanogenesis at great depth in the Siljan impact structure, Sweden
}

\author{
HENRIK DRAKE $^{1}$, MAGNUS IVARSSON ${ }^{2,3}$, CHRISTINE \\ HEIM $^{4}$, STEFAN BENGTSON ${ }^{3}$, VENETA BELIVANOVA ${ }^{3}$, \\ MARTIN WHITEHOUSE ${ }^{3}$ \\ ${ }^{1}$ Linnæus University, Sweden, henrik.drake@Inu.se \\ ${ }^{2}$ University of Southern Denmark, Denmark \\ ${ }^{3}$ Swedish Museum of Natural History, Sweden \\ ${ }^{4}$ Georg-August University, Göttingen, Germany
}

Recent findings of both active and fossilized communities suggest that eukaryotes, such as fungi, may inhabit extremely energy-poor and anoxic environments including deep within the fractured igneous crust. In common with anaerobic fungi in rumens of herbivores, the deep subsurface fungi have been proposed to occur in syntrophic relationships with prokaryotes $^{1,2}$. The deep biosphere may be the largest fungal habitat on our planet, but the knowledge of the metabolisms and syntrophic relationships of fungi in this environment is still scarce. Here we report findings of fossilized carbonaceous, chitin-bearing fungal hyphae at $\sim 540 \mathrm{~m}$ depth below the groundsurface in fractured bedrock of the Devonian Siljan impact structure, the largest crater in Europe. Fine-grained calcite that is intergrown with, and precipitated on, the fungi is highly ${ }^{13} \mathrm{C}$-enriched, suggesting it formed following methanogenesis in situ. The fungi grow from a biofilm of bituminous material and seep oil, originating from overlying black shale in the crater rim. Anaerobic fungi have hydrogenosomes instead of mitochondria and we propose that the heterotrophic fungi decompose the bitumen and produce $\mathrm{H}_{2}$ which fuels the syntrophic autotrophic methanogens (and sulfate reducers). Previously reported U-Pb dating shows that the calcite is $\sim 39$ million years old ${ }^{3}$, which infers the first timing constraints of fossilized fungi in the continental igneous crust. These findings suggest that fungi may be a widespread decomposer of seeped sedimentary hydrocarbons and a provider of $\mathrm{H}_{2}$ to the prokaryotic methane forming communities in the vast rock hosted deep biosphere environment.

1. Drake, et al. Anaerobic consortia of fungi and sulfate reducing bacteria in deep granite fractures. Nature Comm, 2017. 8. https://doi.org/10.1038/s41467-017-00094-6

2. Ivarsson, et al. Fungi in Deep Subsurface Environments, Advances Appl. Microbiol. 2018, p. 83-116.

3. Drake, et al., Timing and origin of natural gas accumulation in the Siljan impact structure, Sweden. Nature Comm, 2019:10 https://doi.org/10.1038/s41467-019-12728-y 